\title{
Novel aspects of the microstructure of PP/PA blends prepared by reactive compounding as studied by microhardness
}

\author{
H.G. FRITZ, Q. CAI \\ Institut für Kunststofftechnologie (IKT), University of Stuttgart, Boeblinger \\ Strasse 70, 70199 Stuttgart, Germany \\ M.E. CAGIAO, L. GIRI, F.J. BALTÁ CALLEJA \\ Instituto de Estructura de la Materia, CSIC, Serrano 119, 28006 Madrid, Spain
}

The microhardness of injection-moulded i-polypropylene/polyamide (iPP/PA) blends prepared by reactive compounding was determined. The formulation rules and processing technology for the preparation of these alloys was reported previously. iPP/PA compositions between $100 / 0$ and 50/50 using functionalized PP with various degrees of mainchain grafting, were investigated. It is shown that the deviation of microhardness from the additivity law of the single components is mainly due to a decrease in the crystallinity of the iPP phase. The results are discussed in the light of the microstructural variations as revealed by X-ray diffraction methods.

\section{Introduction}

The properties of polymers can be modified to a great extent by alloying them with other polymeric materials [1]. The preparation of polymer alloys by reactive blending has been shown to be a powerful method which brings together the advantageous properties of the starting components and minimizes their disadvantages [2]. Formulation rules and process technology to develop injection-moulded i-polypropyplene/polyamide (iPP/PA) alloys and thermoplastic elastomers as well as the property profiles of the resulting products have been recently reported $[3,4]$. If PA is present in the blend as a finely dispersed phase, and is covalently linked to iPP via linkage molecules, then a stable two-phase material results. Such blends may be created from a binary system in which the entire PP matrix is subjected to a grafting reaction prior to the alloying step $[5,6]$. Maleic anhydride (MAH) which is a highly efficient and wellknown linkage molecule has been used to initiate radically the functionalization of polypropylene. These types of polymer blend absorb relatively little water, show an increased stiffness and have an interesting cost constellation. Their mechanical properties and heat distortion temperatures depend to a high degree on the resulting blend morphology. Volume and viscosity ratios of blend components as well as interfacial surface tensions, determine the morphology formation. Fig. 1a and $\mathrm{b}$ demonstrates the typical morphologies for the micro-disperse PA-distribution in the continuous iPP-phase, and the co-continuous iPP/PA structure, respectively.
The aim of the present study was to characterize these iPP/PA alloys by means of two techniques: (i) microindentation hardness, and (ii) $\mathrm{X}$-ray diffraction both at small and wide scattering angles. The use of microindentation hardness, $H$, is now well established as a powerful technique to measure the yield properties (yield stress) and accurately determine changes in morphology and microstructure of polymers [7-9]. In the present work, we have studied the mechanical properties and the X-ray diffraction patterns of a series of injection-moulded $\mathrm{PP} / \mathrm{PA}$ reactive blends with different compositions and various grafting ratios and degrees of linkage between the polymers. It is known that process variables induce substantial changes in the microstructure of the moulded material [10]. As a result, the mechanical properties can conspicuously vary on the plane surfaces and across the thickness of the injection-moulded samples [11-13]. The results of microhardness variations occurring across the moulding thickness and the correlations to microstructure are reported.

\section{Experimental procedure}

\subsection{Materials}

A series of i-polypropylene/polyamide (iPP/PA) blends with different compositions and various grafting ratios, $r$, were prepared; the details are given in Table I. The iPP matrix (Hostalen PPH 0150) was functionalized by grafting with maleic anhydride (MAH) prior to the alloying step. The MAH molecules grafted on to PP can react with terminal amine 

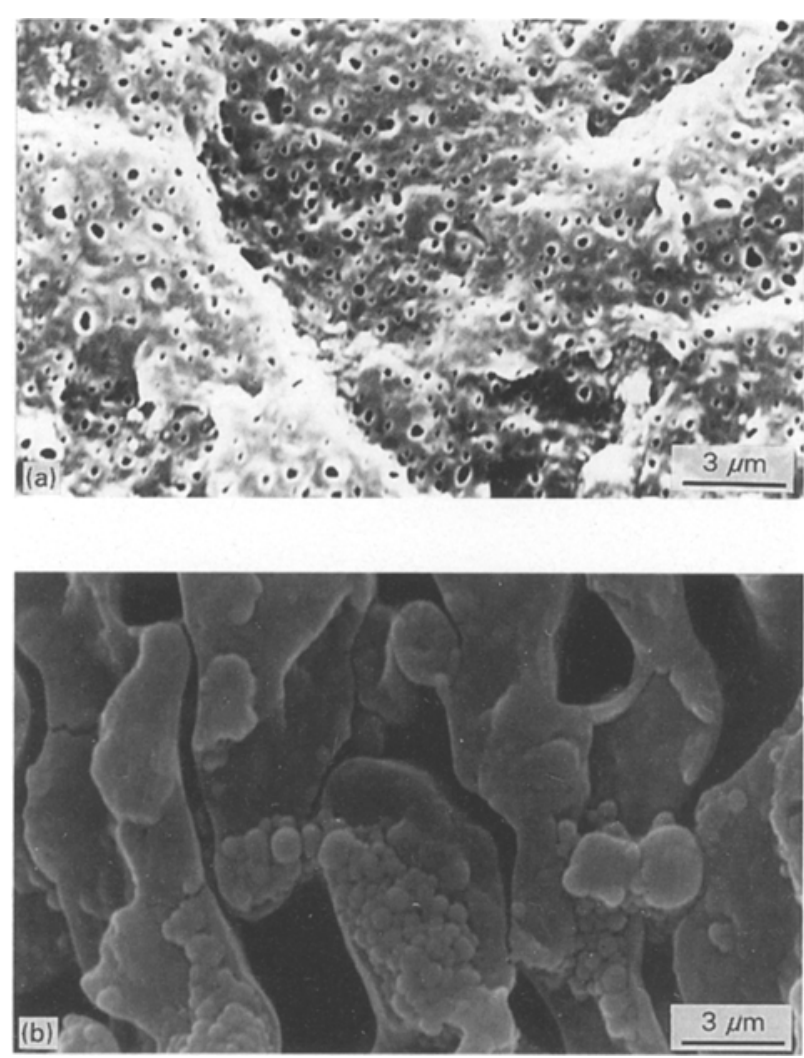

Figure I Morphologies of iPP/PA blends: (a) micro-disperse PAdistribution and (b) a co-continuous PP/PA structure.

TABLE I Values of the proportion of added MAH (a-MAH), grafting ratio (g-MAH) and of the proportion of $\mathrm{PA}$ covalently linked to PP ( $\mathrm{r}-\mathrm{A})$ for the various blends investigated

\begin{tabular}{lllll}
\hline Sample & $\begin{array}{l}\text { PP/PA } \\
(\%)\end{array}$ & $\begin{array}{l}\text { a-MAH } \\
(\%)\end{array}$ & $\begin{array}{l}\text { g-MAH } \\
(\%)\end{array}$ & $\begin{array}{l}\text { r-A } \\
(\%)\end{array}$ \\
\hline 1 & $80 / 20^{\mathrm{a}}$ & 3.0 & 2.07 & 80.3 \\
2 & $65 / 35^{\mathrm{a}}$ & 3.0 & 2.07 & 85.7 \\
3 & $50 / 50^{\mathrm{a}}$ & 3.0 & 2.07 & 88.4 \\
4 & $50 / 50^{\mathrm{a}}$ & 2.0 & 1.32 & 72.4 \\
5 & $65 / 35^{\mathrm{a}}$ & 1.0 & 0.87 & 89.6 \\
6 & $80 / 20^{\mathrm{b}}$ & 0.5 & 0.20 & 78 \\
7 & $70 / 30^{\mathrm{b}}$ & 0.5 & 0.20 & 88 \\
\hline
\end{tabular}

aPA: nylon 6,6

${ }^{b}$ PA: nylon 6.

groups of the PA by reactive extrusion. For this purpose PA6 (BASF, Ultramid B3) and PA6.6 (HoechstCelanese, A1) were used. The fraction of polyamide that is covalently linked to PP is determined by the grafting ratio, g-MAH, of functionalized PP. Specimens were finally prepared in the usual dumb-bell shape for mechanical testing, by means of injection moulding (melt temperature $275^{\circ} \mathrm{C}$; mould temperature $60^{\circ} \mathrm{C}$ ).

\subsection{X-ray diffraction experiments}

The wide-angle $X$-ray diffraction patterns of the injection-moulded materials were taken in the central part, across the thickness of the mouldings. The X-ray scattering patterns were obtained using a Philips diffractometer with a flat camera with nickel-filtered $\mathrm{Cu} K_{\alpha}$ radiation from a $40 \mathrm{kV}, 40 \mathrm{~mA} \mathrm{X}$-ray source. The sample to film distance was $40 \mathrm{~mm}$. Small-angle X-ray scattering (SAXS) patterns were obtained with a point collimation Rigaku camera using a sample to film distance of $300 \mathrm{~mm}$. A rotating anode $\mathrm{X}$-ray generator using nickel-filtered $\mathrm{Cu} K_{\alpha}$ radiation with a fine focus working at $40 \mathrm{kV}$ and $70 \mathrm{~mA}$ was used.

\subsection{Hardness measurements}

Microhardness was measured at room temperature using a Leitz Tester adapted with a square-based diamond indentor. The $H$ value was derived from the residual projected area of indentation according to the expression $H=k P / d^{2}$ (MPa), where $d$ is the length of the impression diagonal in metres, $P$ the contact load applied in $\mathrm{N}$ and $k$ is a geometrical factor equal to 1.854. A loading cycle of $0.1 \mathrm{~min}$ and loads of 0.5 and $1 \mathrm{~N}$ were used. Microhardness was measured in the centre of each moulding from indentations made across the width of the sample, i.e. in the $y$ direction in Fig. 2.

\section{Results}

\subsection{Wide-angle X-ray scattering (WAXS)}

Fig. 3 shows the WAXS patterns of the homopolymers iPP and PA and of some typical iPP/PA reactive blends.Fig. $3 \mathrm{~b}$ corresponds to the WAXS patterns of PP with 3\% MAH. While the PP sample (Fig. 3a) shows a well-oriented fibre structure, the PA sample (Fig. 3f) exhibits an isotropic and weaker disoriented $\mathrm{X}$-ray diffraction pattern. The main reflections of the PP pattern are identified with (110), (040), (130), (111) and (041) spacings of the $\alpha$-modification of isotactic polypropylene (iPP). The two reflections of the PA correspond to (110) and (111) spacings of a triclinic cell.

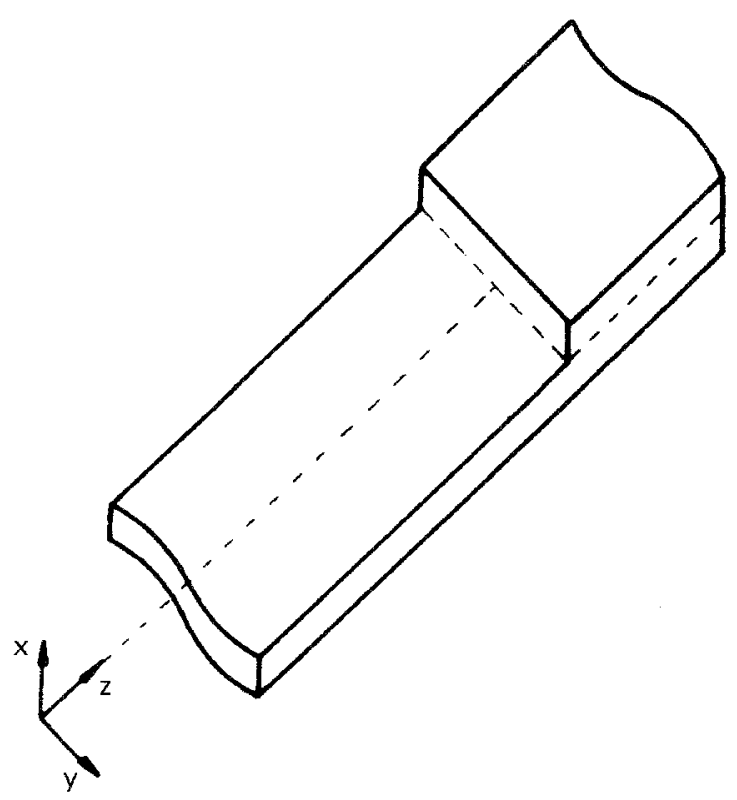

Figure 2 Geometry of the cut on an injection-moulded PP/PA bar. $z$ is the injection direction; $x$ the normal to the surface. Indentations were made on the $y z$ plane. 

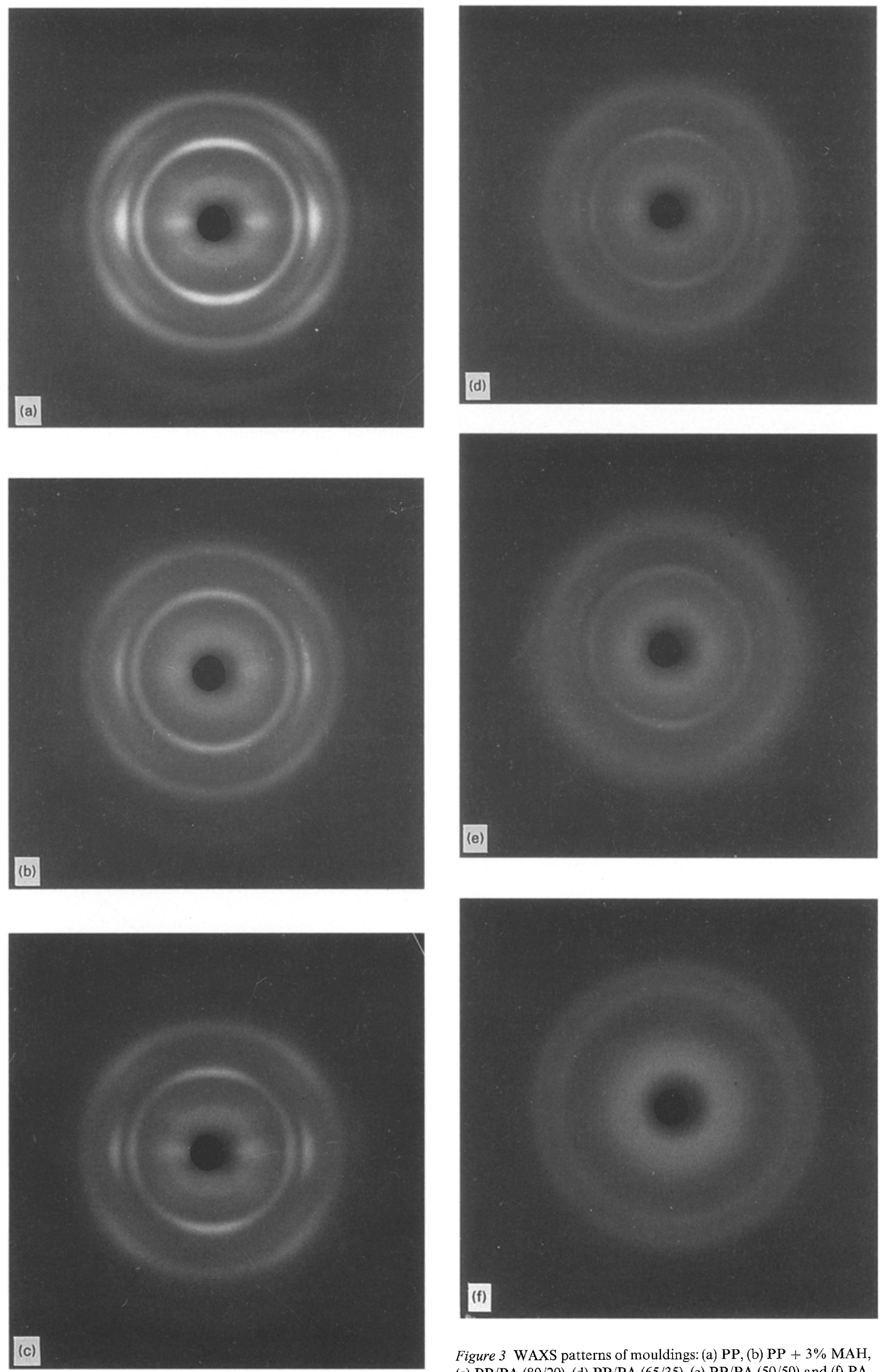

Figure 3 WAXS patterns of mouldings: (a) PP, (b) $\mathrm{PP}+3 \% \mathrm{MAH}$, (c) PP/PA (80/20), (d) PP/PA (65/35), (e) PP/PA (50/50) and (f) PA 
7The wide-angle $X$-ray scattering patterns of the iPP/PA blends (Fig. 3c-e) show the oriented fibre diagram of the iPP $\alpha$-phase, superposed on the faint dioriented reflections of the PA.

The $h k 0$ reflections appear on the equator indicating the $c$-axis orientation parallel to the injection direction. This shows that the iPP crystals are oriented in the iPP/PA blends with the molecular axis along the injection direction. However, one sees that with increasing PA concentration the structure of iPP becomes gradually less oriented. For the $50 / 50$ blend (Fig. 3e) the orientation of the iPP phase is minimum. It is noteworthy that in all blends, the 130 reflection shows a very weak scattering intensity. In addition, the 110 reflection (innermost one) is also oriented along the meridian. This suggests that there is a fraction of crystals with the $c$-axis normal to the injection direction. On the other hand, the PA phase in the blends is disoriented and the scattering intensity of this phase, even in the case of the PA homopolymer, is very much lower than that of the iPP phase. Therefore, for PA concentrations smaller than $50 \%$ the Xray scattering from the $\mathrm{PA}$ phase can hardly be seen.

\subsection{Small-angle $X$-ray scattering (SAXS)}

The iPP (injection-moulded) sample shows intense circular meridional spots (Fig. 4a). This means that the PP lamellar crystals are efficiently stacked with the lamellar normal parallel to the injection direction. The PP sample with $3 \% \mathrm{MAH}$ shows a SAXS pattern with much fainter and more disoriented scattering maxima (Fig. 4b). This result suggests that the presence of MAH substantially reduces the perfection and orientation of the stacks of PP lamellae. The blend with high PP content (80/20) also shows circular meridional spots (Fig. 5b), although the scattering intensity is smaller. With increasing PA content the scattering intensity markedly decreases and the two circular meridional spots are gradually transformed into fainter scattering ares (Fig. $5 \mathrm{c}$ and d). The angular constancy of the meridional maximum indicates that the long period, $L$, corresponding to the stacks of iPP lamellae, is independent of composition (see Fig. 6). Thus, the values of $L$ obtained within the range $L \sim 16.5-$ $17.5 \mathrm{~nm}$, only depend on the processing conditions (mould temperature). Furthermore, the small-angle scattering intensity of the iPP lamellar stacks decreases with increasing PA content (Fig. 7). This is obviously the result in the reduction of the number of iPP lamellar stacks with increasing PA concentration. For the PA homopolymer the scattering pattern shows an extremely weak diffraction ring, not detectable for the exposure time used, which reveals a disorientation of $P A$ lamellae with a long period of $L \approx 10.5 \mathrm{~nm}$, However, for the PP/PA blends evidence for scattering maxima near $L \sim 10.5 \mathrm{~nm}$ is not obtained. This indicates that the PA crystallites do not show such a well-organized structure as the iPP lamellar stacks.

\subsection{Microhardness measurements}

The microhardness profile in the $y$-direction shows, in all samples, the highest values near the surface of each
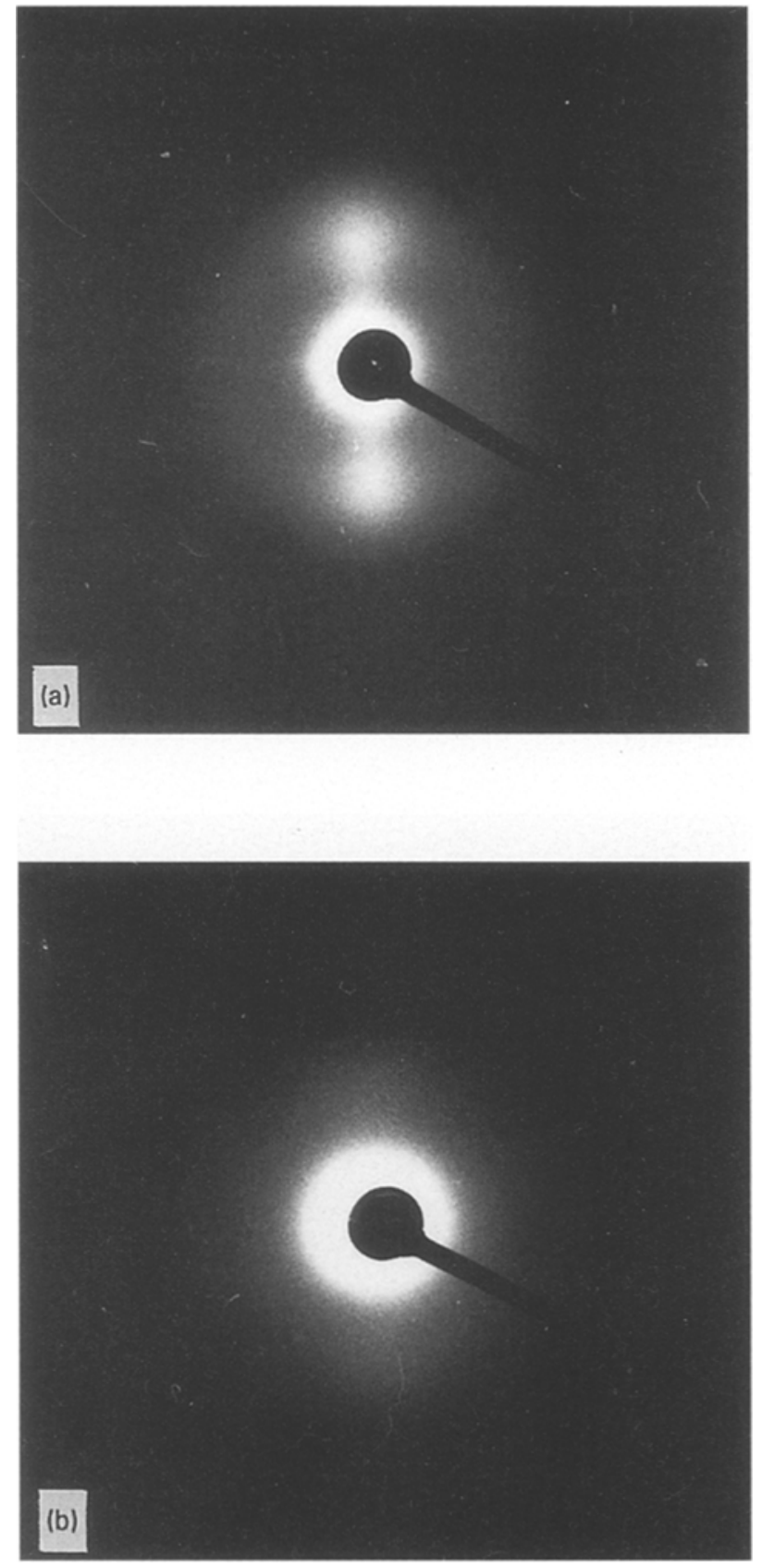

Figure 4 SAXS patterns of mouldings (a) PP and (b) PP $+3 \%$ MAH.

moulding. One typical profile for the sample $(65 / 35)$ is shown in Fig. 8. The presence of a hard skin in the injection-moulded samples is probably due to the influence of the shear-flow component at the wall of the moulds. Measurements carried out along the $z$-direction do not show any appreciable variation in the $H$ value. We have calculated the average value of $H$ from the data measured across the width $(y$-direction) of each sample.

The experimental microhardness values, $H_{\text {exp }}$, of the iPP/PA blends, the $H$ values derived from Tabor relation $\left(H \sim 3 \sigma_{\mathrm{y}}\right)[7,8]$, using yield-stress data published elsewhere for these samples [6], and the crystallinity values derived from calorimetry of the iPP and PA components within each blend, $\alpha_{\mathrm{Pp}}$ and $\alpha_{\mathrm{PA}}$, are collected as function of composition, $\phi$, in Table II. 

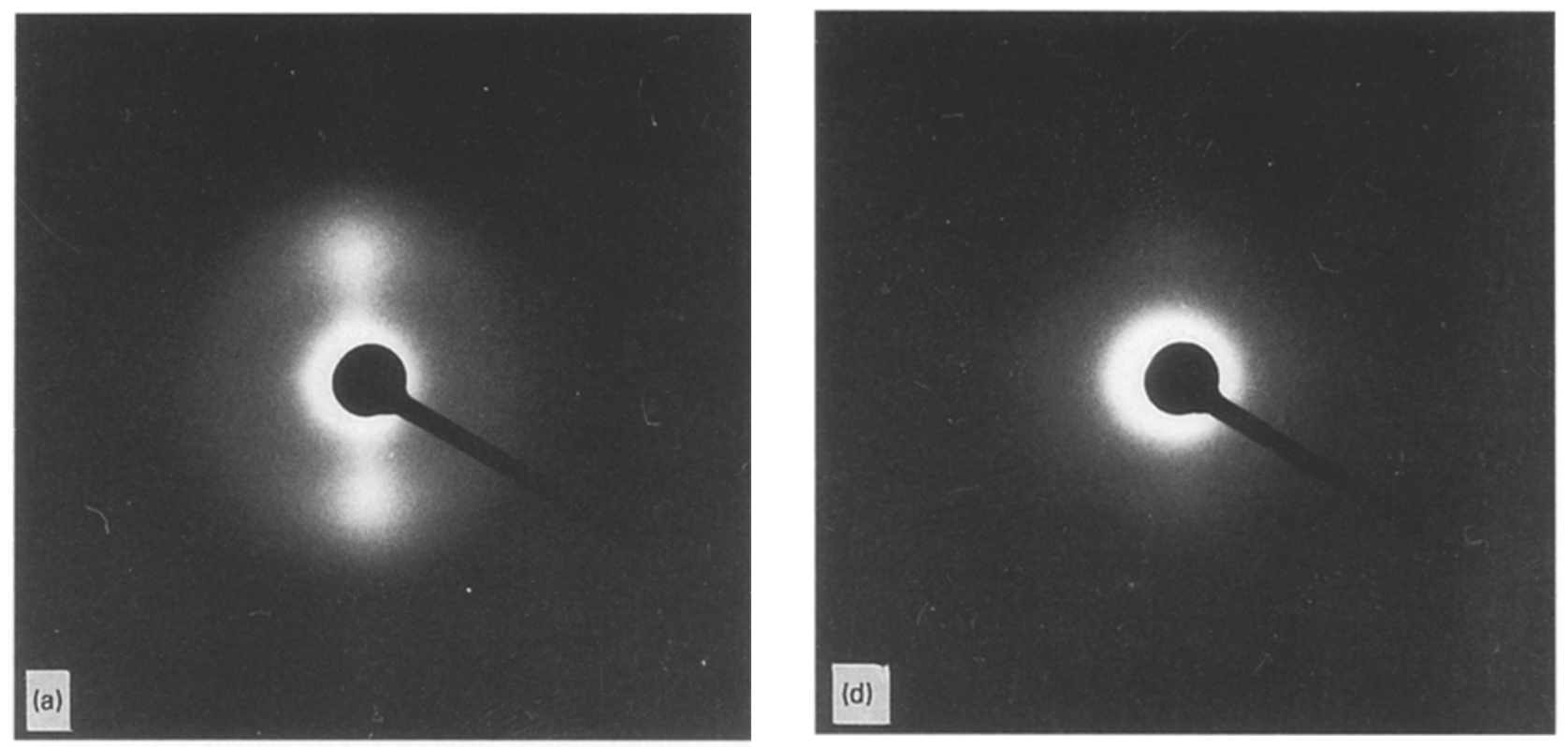

Figure 5 SAXS patterns of (a) PP, (b) PP/PA (80/20), (c) PP/PA (65/35) and (d) PP/PA (50/50).
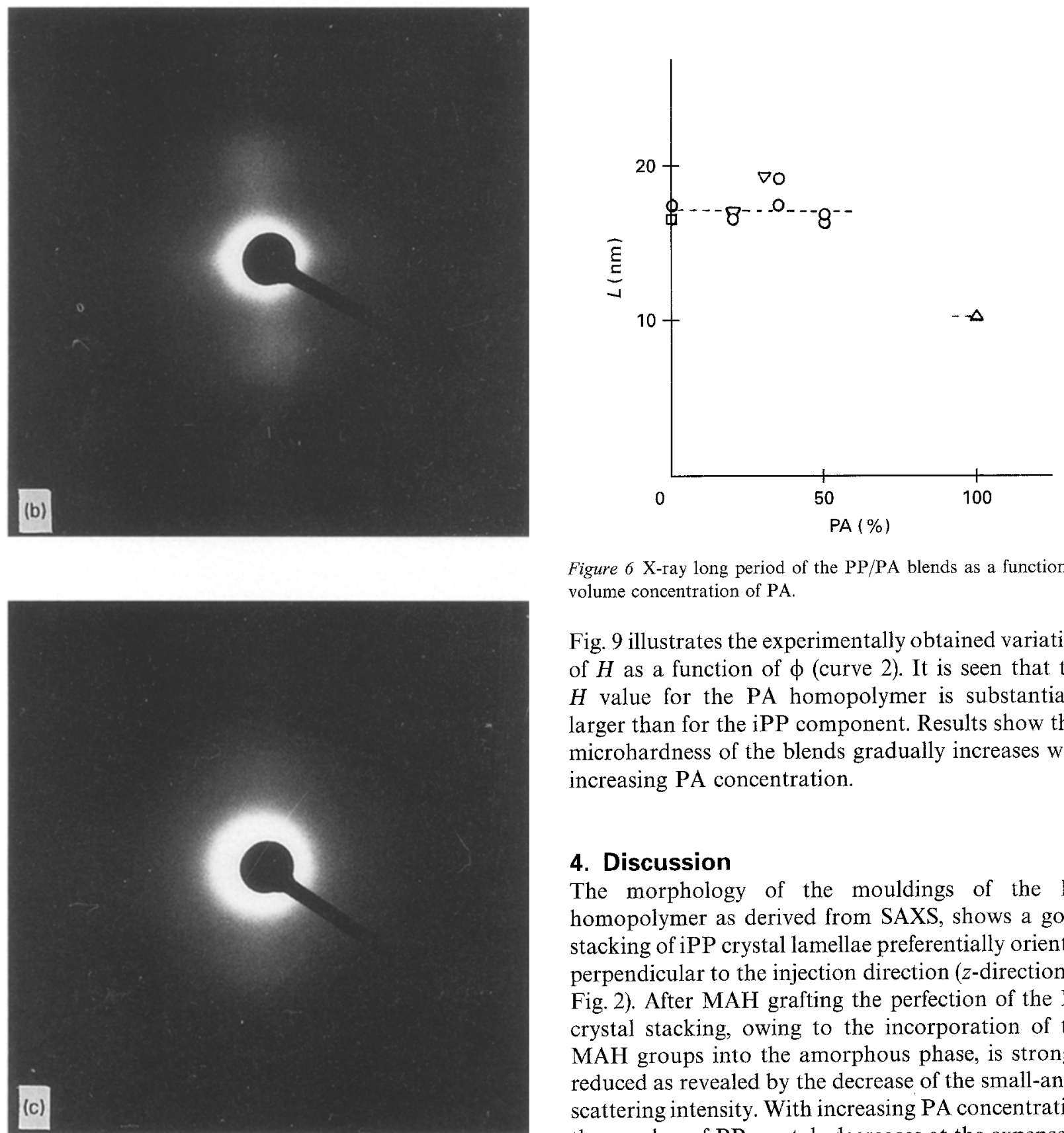

Figure 6 X-ray long period of the PP/PA blends as a function of volume concentration of $\mathrm{PA}$.

Fig. 9 illustrates the experimentally obtained variation of $H$ as a function of $\phi$ (curve 2). It is seen that the $H$ value for the PA homopolymer is substantially larger than for the iPP component. Results show that microhardness of the blends gradually increases with increasing PA concentration.

\section{Discussion}

The morphology of the mouldings of the PP homopolymer as derived from SAXS, shows a good stacking of $\mathrm{PP}$ crystal lamellae preferentially oriented perpendicular to the injection direction $(z$-direction in Fig. 2). After MAH grafting the perfection of the PP crystal stacking, owing to the incorporation of the MAH groups into the amorphous phase, is strongly reduced as revealed by the decrease of the small-angle scattering intensity. With increasing PA concentration the number of PP crystals decreases at the expense of 


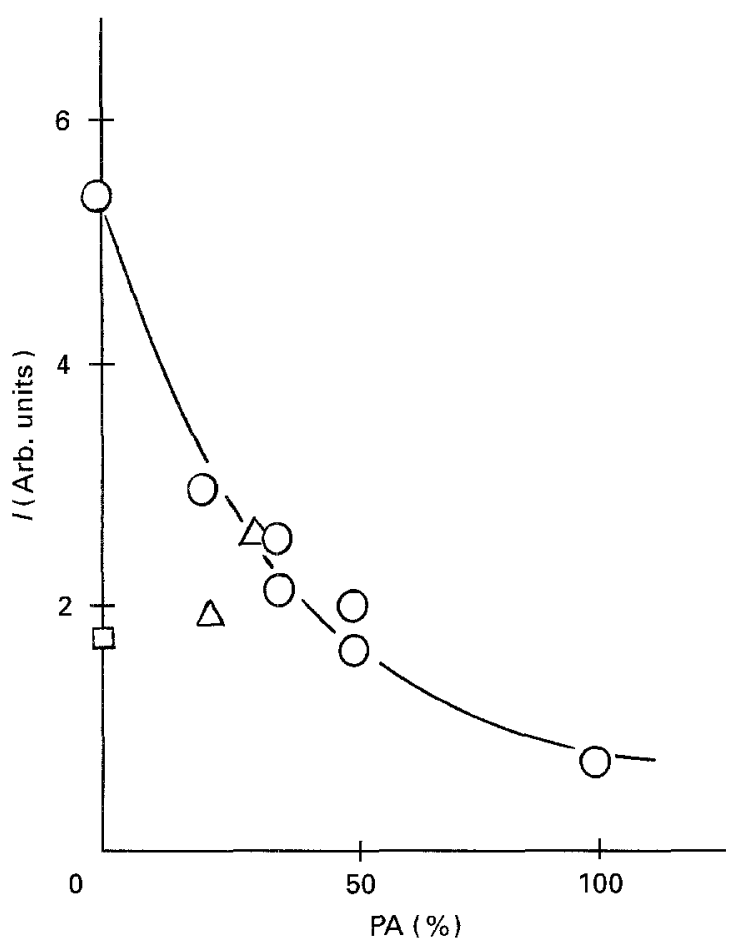

Figure 7 Small-angle X-ray scattering intensity of PP/PA blends versus volume concentration of PA.

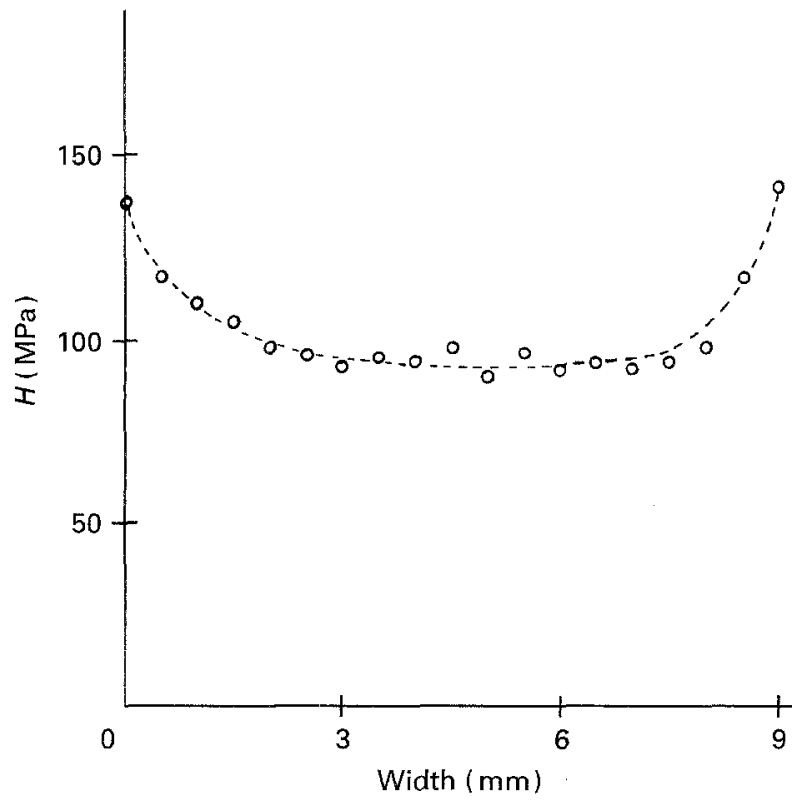

Figure 8 Microhardness profile along the $y$-direction obtained from measurements at the inner $y z$ surface of the moulding PP/PA $(65 / 35)(r=0.86)$.

the PA phase, giving rise to the observed decrease in scattering intensity. The long period of the iPP stacking periodicity depends only on the temperature of the mould, because it is known to occur in other injectionmoulded polymers [15], and, therefore, is independent of composition. On the other hand, the PA crystals in the blends are disoriented and randomly segregated into the PA phase so that they do not produce discrete maxima in the SAXS patterns.

From the WAXS patterns one observes that the PP phase shows a biaxial orientation of crystals perpendicular and parallel to the $z$-direction. With increasing PA concentration, the PP crystal orientation diminishes and the crystallinity of PP phase, $\left(\alpha_{\mathrm{pP}}\right)$, as revealed by DSC, decreases.

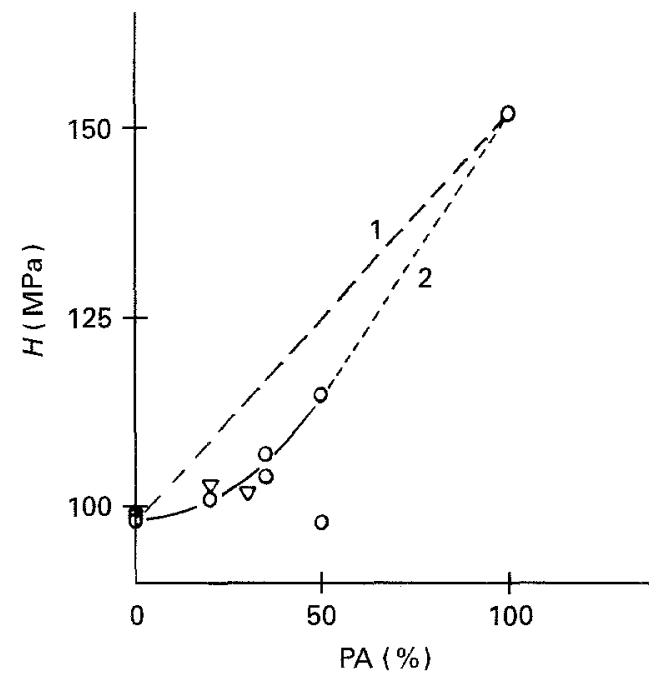

Figure 9 Microhardness of iPP/PA blends as a function of the volume concentration of PA. (1) Additivity behaviour from Equation 4 with the use of crystallinity values of the individual homopolymers. (2) $H$ values from Equation 4 using $\alpha_{P P}$ and $\alpha_{P A}$ data (Table II). $(O, \nabla)$ Experimental data.

Furthermore, the experimental results of Fig. 9 show a conspicuous deviation from the hardness additivity law

$$
H=\phi H^{\mathrm{PA}}+(1-\phi) H^{\mathrm{PP}}
$$

(where $\phi$ and 1- $\phi$ are, respectively, the weight fractions of PA and iPP) which corresponds to the straight line 1 in Fig. 9.

If we use the parallel model of hardness additivity for the PA phase we can write

$$
H^{\mathrm{PA}}=\alpha_{\mathrm{PA}} H_{\mathrm{c}}^{\mathrm{PA}}+\left(1-\alpha_{\mathrm{PA}}\right) H_{\mathrm{a}}^{\mathrm{PA}}
$$

and for the PP phase

$$
H^{\mathrm{PP}}=\alpha_{\mathrm{PP}} H_{\mathrm{c}}^{\mathrm{PP}}+\left(1-\alpha_{\mathrm{PP}}\right) H_{\mathrm{a}}^{\mathrm{PP}}
$$

where $\mathrm{H}_{\mathrm{c}}^{\mathrm{PA}}$ and $\mathrm{H}_{\mathrm{c}}^{\mathrm{PP}}$ are the crystal hardness values of $\mathrm{PA}$ and PP respectively and $\mathrm{H}_{\mathrm{a}}^{\mathrm{PA}}$ and $\mathrm{H}_{\mathrm{a}}^{\mathrm{PP}}$ are the corresponding amorphous hardness values. By combination of Equations 2 and 3 we are led to the expression

$$
\begin{aligned}
H= & \phi\left[\alpha_{\mathrm{PA}} H_{\mathrm{c}}^{\mathrm{PA}}+\left(1-\alpha_{\mathrm{PA}}\right) H_{\mathrm{a}}^{\mathrm{PA}}\right] \\
& +(1-\phi)\left[\alpha_{\mathrm{PP}} H_{\mathrm{c}}^{\mathrm{PP}}+\left(1-\alpha_{\mathrm{PP}}\right) H_{\mathrm{a}}^{\mathrm{PP}}\right]
\end{aligned}
$$

which describes the microhardness of the iPP/PA blends in terms of the hardness values of the independent crystalline and amorphous components. From Table II one sees that the PA component hampers the crystallization capability of PP and, therefore, $\alpha_{\mathrm{PP}}$ decreases with increasing PA concentration. On the other hand, the presence of iPP crystals does not seem to inhibit the crystallization level of PA and $\alpha_{P A}$ remains nearly constant. From SAXS results we have seen that $L=$ const. and from calorimetric data $\left(T_{\mathrm{m}}\right.$ for both PP and PA is constant with composition), we conclude that the crystal thickness, $l_{\mathrm{c}}$, is also constant (the fact that $l_{\mathrm{c}}=$ constant simplifies the calculation of the microhardness, as we have shown that $H_{\mathrm{c}}$ is an increasing function of $l_{\mathrm{c}}$ ) $[8,9]$. Then, if we take into account the crystallinity depression measured for the $\mathrm{PP}$ component in Equation 4, use for $H_{\mathrm{c}}^{\mathrm{PP}}=145 \mathrm{MPa}$ 
TA BLE II Experimental and calculated values of microhardness and crystallinity derived from DSC of iPP and PA reactive blends as a function of composition

\begin{tabular}{|c|c|c|c|c|c|c|c|c|}
\hline Sample & $\mathrm{iPP} / \mathrm{PA}$ & $r$ & $\alpha_{\mathrm{PP}}$ & $\alpha_{\mathrm{PA}}$ & $\begin{array}{l}H_{\mathrm{PP}}(\mathrm{calc}) \\
(\mathrm{MPa})\end{array}$ & $\begin{array}{l}H_{\mathrm{exp}} \\
(\mathrm{MPa})\end{array}$ & $\begin{array}{l}H_{\text {calc }} \\
(\mathrm{MPa})\end{array}$ & $\begin{array}{l}H_{\text {Tabor }} \\
(\mathrm{MPa})\end{array}$ \\
\hline PP & $100 / 0$ & - & 0.60 & - & 98 & 98 & 98 & 102 \\
\hline $\mathrm{PP}_{\mathrm{MAH}}$ & $100 / 0$ & - & 0.61 & - & - & 99 & - & - \\
\hline 1 & $80 / 20^{\mathrm{a}}$ & 0.80 & 0.57 & 0.34 & 88 & 101 & 101 & 105 \\
\hline 2 & $65 / 35^{\mathrm{a}}$ & 0.86 & 0.50 & 0.33 & 79 & 104 & 105 & 110 \\
\hline 3 & $50 / 50^{\mathrm{a}}$ & 0.88 & 0.48 & 0.31 & 76 & 115 & 114 & 115 \\
\hline 4 & $50 / 50^{\mathrm{a}}$ & 0.72 & 0.55 & 0.31 & 85 & 98 & 118 & - \\
\hline 5 & $65 / 35^{\mathrm{a}}$ & 0.90 & 0.64 & 0.33 & 97 & 107 & 116 & - \\
\hline 6 & $80 / 20^{\mathrm{b}}$ & 0.78 & - & - & - & 103 & - & - \\
\hline 7 & $70 / 30^{\mathrm{b}}$ & 0.88 & - & - & - & 102 & - & - \\
\hline PA & $0 / 100$ & - & - & 0.33 & - & 152 & 152 & 150 \\
\hline
\end{tabular}

aAs: nylon 6,6.

${ }^{\mathrm{b} P A}$ : nylon 6.

and for $H_{\mathrm{a}}^{\mathrm{PP}}=15 \mathrm{MPa}[16]$, and let $H^{\mathrm{PA}}=152 \mathrm{MPa}$, we are led to curve 2 in Fig. 9. The agreement between experimental and calculated data is good and supports the concept that the depression of microhardness values is mainly caused by the crystallinity decrease of the PP phase which creates new amorphous regions outside the PP lamellar stacks.

Only the $H$ value for sample 4 in Fig. 9 is much lower than that expected from Equation 4. The only feature from this sample which deviates from the other blends is the low $r$-value $(0.72)$. In particular, the mechanical properties especially the tensile strength of physical iPP/PA-blends, generated from ungrafted polypropylene, are significantly lower than those of the pure iPP matrix [3]. Therefore, the low $H$ value obtained in Fig. 9 suggests a reduced interaction between the two phases.

Finally, it is noteworthy that the agreement found between $H_{\exp }$ and $H_{\text {Tabor }}$ values in Table II emphasizes the value of the microhardness technique in correlating micromechanical data connected with the morphology of the blends and the macroscopic mechanical results.

\section{Conclusion}

In conclusion, the hardness values of the injectionmoulded reactive iPP/PA blends can be described in terms of at least four contributions: (a) the crystalline $\alpha$-phase which shows a $c$-axis molecular orientation parallel to the injection-moulding direction, (b) the amorphous iPP-phase which is preferentially located within the stacks of lamellae which are perpendicular to the injection direction, (c) the crystalline PA phase which is unoriented and does not show any apparent regular lamellar periodicity, and (d) the amorphous glassy PA phase. It is shown that the presence of PA throughout the range of blends inhibits the crystallization of iPP and induces a depression of crystallinity in the form of amorphous regions created outside the iPP lamellar stacks, causing a depression of the hardness values from the additivity law of single components. Factors such as the main-chain grafting ratio and the degree of linkage between iPP and PA chains can strongly affect the nature of the amorphous network and influence the mechanical yielding of the material as revealed by microhardness.

\section{Acknowledgements}

The authors are grateful to CICYT (Grant 0740/94E), Spain, for the generous support of this investigation. One of us (L. Giri) thanks the tenure of a grant of the Ministerio de Educación y Ciencia, Spain. H. G. Fritz and Q. Cai acknowledge Hoechst AG, Frankfurt, for the support to the iPP/PA-blend project.

\section{References}

1. H. G ELIAS, "Macromolecules. Vol. 2. Synthesis, materials and technology" 2nd Edn. (Plenum, New York, London, 1984) p. 1147.

2. M. LAMBLA, X. YU and S. LOREK, "Coreactive polymer alloys" ACS Symposia Series (American Chemical Society, Washington, 1989) p. 395.

3. H. G. FRITZ, Q. CAI and U. BÖLZ, 13 Stuttgarter Kunststoffkolloquium, Stuttgart, 17/18 March 1993; Abstract Book, p. 5-23.

4. H. G. FRITZ, Q. CAI, U. BÖLZ and R. ANDERLIK, in "IUPAC International Conference on Advanced Polymer Materials", edited by H. J. Jacobasch, Dresden, 6-9 September 1993, p. 5.

5. S. J. PARK, B. K. KIM and H. M HONG, Eur. Polym. J. 26 (1990) 131.

6. H. G. FRITZ, Q. CAI and U. BÖLZ, Kunststoffe 83 (1993) 439.

7. F. J. Baltá Calleja, Adv. Polym. Sci. 66 (1985) 117.

8. F. J. Baltá CAlleja and H. G. Kilian, Coll. Polym. Sci. 266 (1988) 29.

9. F. J. BALTÁ CALLEJA, C. SANTA CRUZ, C. SAWATARI and T. ASANO, Macromolecules 23 (1990) 5352.

10. F. J. BALTÁ CALLEJA, C. SANTA CRUZ, and T. ASANO, J. Polym. Sci. Polym. Phys. 31 (1993) 557.

11. F. JOHANNABER, "Injection-moulding machines", 2nd Edn (Hanser, New York 1985) p. 39.

12. D. R. RUEDA, F. J. BALTÁ CALLEJA, R. K. BAYER and H. G. ZACHMANN, J. Macromol. Sci. Phys. B28 (2) (1989) 265 .

13. F. J. BALTÁ CALLEJA, J. BARANOWSKA, D. R. RUEDA and R.K. BAYER, J. Mater. Sci. 28 (1993) 6074.

14. D. R. RUEDA, L. KUBERA, F. J. BALTA CALLEJÁ and R. K. BAYER, J. Mater. Sci. Lett. 12 (1993) 1140.

15. D. R. RUEDA, F. J. BALTÁ CALLEJA and R. K. BAYER, $J$. Mater. Sci. 16 (1981) 3371.

16. F. J. BALTÁ CALLEJA, J. MARTINEZ SALAZAR and T. ASANO, J. Mater. Sci. Lett. 7 (1988) 165.

Received 3 November 1994

and accepted 20 January 1995 